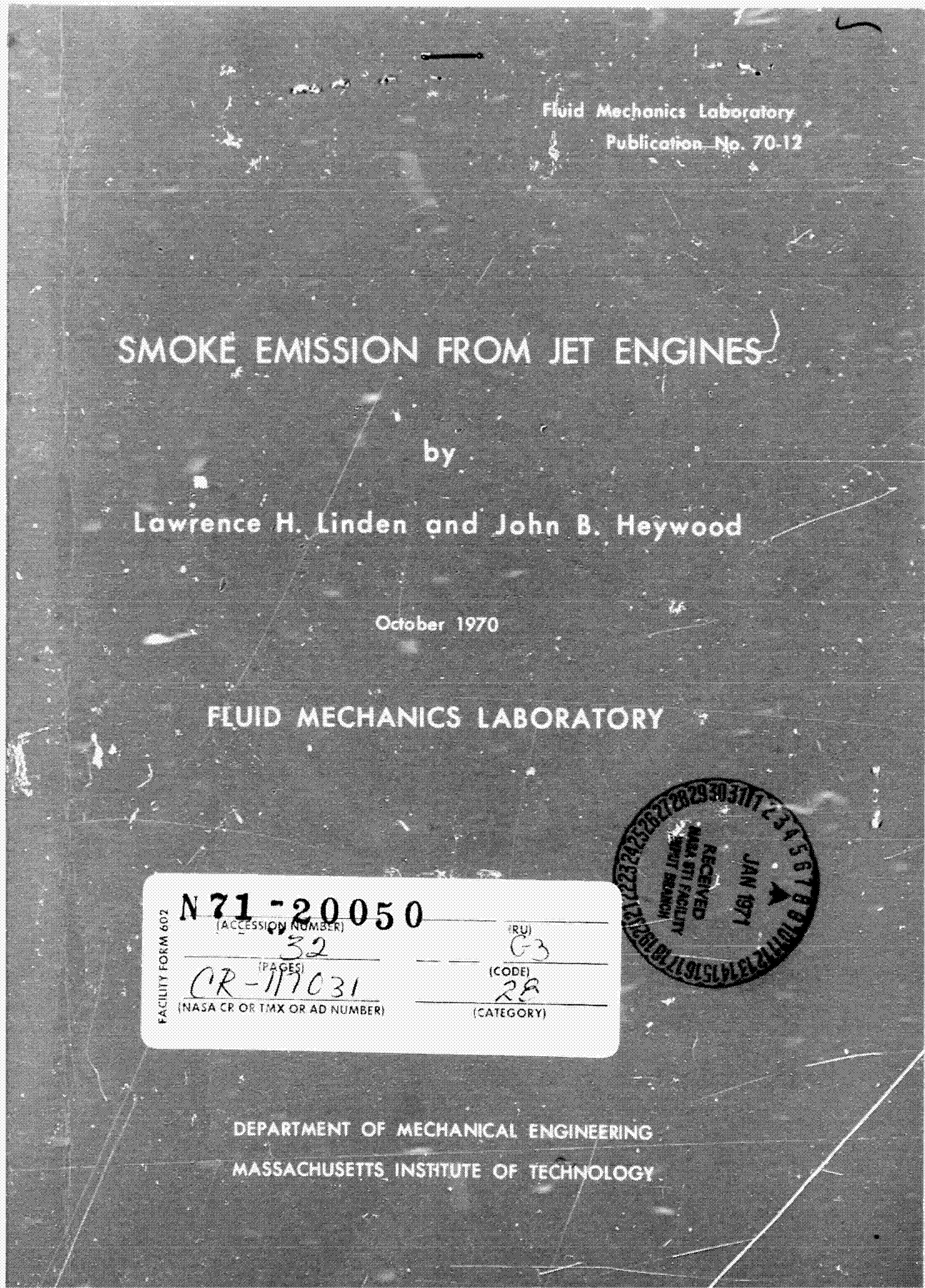


SMOKE EMISSION FROM JET ENGINES

by

Lawrence H. Linden and John R. Heywood

Fluid Mechanfcs Laboratory

Department of Mechanical Engineering

Massachusetts Institute of Technology

This work was supported by NASA Grant NGR 22-00S-378. L.H.L. was supported by a NSF Fellowship

October 1970 


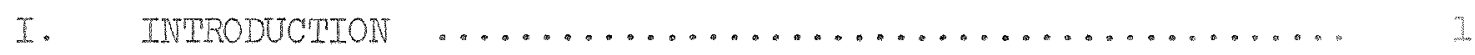

II. GAS TURBINE COMBUSTION $\ldots \ldots \ldots \ldots \ldots$

A. Combustor Description $\ldots \ldots \ldots \ldots \ldots \ldots \ldots \ldots \ldots \ldots \ldots \ldots \ldots \ldots \ldots \ldots \ldots \ldots$

B. The Combustion Process ....................... ?

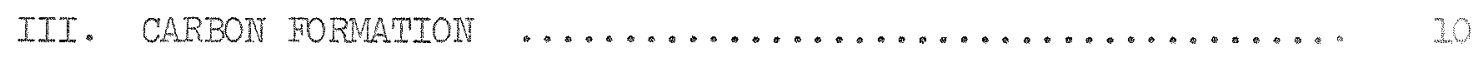

A. Data from Laboratory Flames .................... 10

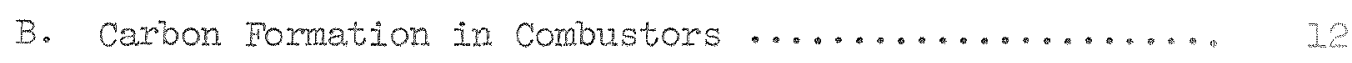

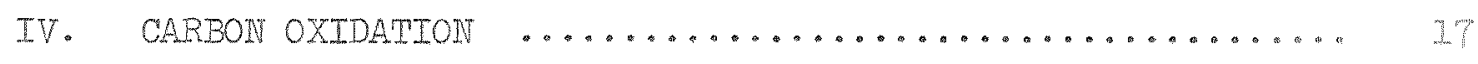

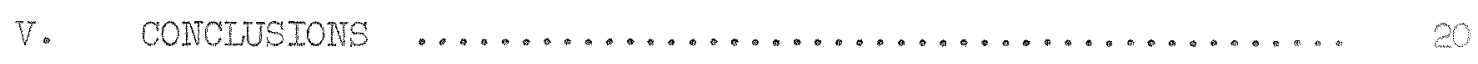

REREREIVCES $\ldots \ldots \ldots \ldots \ldots \ldots \ldots \ldots$

\section{LISI OF IIIUSTRATIONS}

Eigure

1. Cross-section of a Typical Combustor $\ldots \ldots \ldots \ldots . . . . . . . .2$

2. Results of a one-dimensional model secondary zone calculation for Chefuel bumed with $700 \mathrm{~K}$, 15 atm air. Mean primary zone equivalence ratio is 1.2 . Mean eas cemperature T, equivalence ratio $\phi$, nomalized travel time t (time atter entry into secondary zone/secondary zone residence time) and nomalized liner mass flux (local mas flux/mass flux at secondary zone exit) are shom as a function of nomalized position along the secondary zone. Secondary zone length mas 1 foot.

3. Hffect of pressure and equivalence ratio on soot formation ratio for premixed n-pentane-oxygen combustion. Soot formation ratio $s$ is percentage of fuel carbon atoms which emerge from the flane as soot. Fron MacFarlane et al. (1964)...

4. Effect of combustor pressure and overall equivalence ratio on smoke emission of Rolls-Royce RA.24 engine. P.S.U.

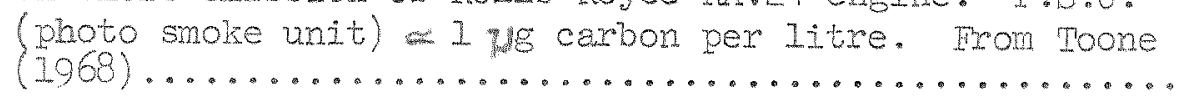




\section{UIST OR IIUUSTRATIONS(COncluded)}

Pigure

5. Regions of available carbon oxidation data compared with region of interest in jet engines.

6. Calculated burning rates of soot particles in adiabatic combustion products of kerosene $\left(\mathrm{C}_{n} \mathrm{E}\right)$ and air at 10,20 , and 30 atm. Combustor inlet air temperatures are 621, 765 , and $865^{\circ} \mathrm{K}$. Soot buming rate expressed as a surface

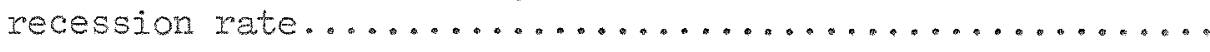


SMOKE EMISSION FROM JET ENGINES

Lawrence H. Linden and John B. Heywood

Mechanical Engineering Department

Massachusetts Institute of Technology, Cambridge, Massachusetts

ABSTRACT--The fundamental processes determining the amount of smoke in the exhaust of a gas turbine engine are examined. First, the configuration of modern combustors and the state of knowledge of the processes ocisurring within the combustor are reviewed. Data from laboratory flame studies of carbon formation are then discussed and correlated with engine and combustor exhaust studies. It is seen that solid carbon is the nonequilibrium product of fuel vapor-air combustion in locally fuel rich zones. Calculations of carbon oxidation rates are then used to show that significant fractions of the carbon formed in the rich regions of the primary zone may be consumed in the leaner regions of the primary zone and in the secondary zone. Finally, combustor design features desirable for minimal exhaust smoke are summarized, and areas where further research would be most teneficiai are identified.

\section{INTRODUCTION}

As a highly visible form of air pollution, the smoky exhausts of modern jet aircraft engines have become a matter of public concern. There exists a large body of data relevant to this problem, ranging from fundamental chəmical kinetics and fluid mechanics studies to combustor development tests. It is the purpose of this paper to review and correlate this work, sumarizing the important results. The emphasis is on defining the underlying physical processes which determine smoke emission from jet engines and how these processes may be controlled to reduce smoke. 
The solid carbon outputs of several modern aircraft jet engtnes are shown in Table 1 . It can be seen that relatively small amounts of carbon are involved. This small departure from complete combustion results in a negligible loss of combustion efficiency. For example, roughly 0.50 per cent fuel emitted as solid carbon, which is a very smoky exhaust, results in a combustion inefficiency of 0.35 per cent (Toone (1968)). Thus concern for combustion efficiency has never caused engine designers to consider smoke a problem. There has been some concern in the military over the visibility of aircraft which smoke, and also about carbon deposits left on aircraft carrier decks (Fiorello (1968)). It is, however, the air pollution aspects of gas turbine smoke that have made it important.

TABLE 1

Solid Carbon Outputs of Aircraft Jet Engines (Mass ratio of solid carbon to fuel,,$\%$ )

\begin{tabular}{|c|c|c|c|}
\hline Engine Model & $\mathrm{J}-57^{\mathrm{a}}$ & $\mathrm{JT}_{\mathrm{TD}}^{\mathrm{b}}$ & $T F-33^{c}$ \\
\hline Take-off & 1.4 & 0.28 & 0.19 \\
\hline Approach & 0.7 & 0.27 & 0.21 \\
\hline Idle & 1.0 & 0.06 & 0.24 \\
\hline
\end{tabular}

${ }^{a}$ George and Burlin (1960)

bozano et a1. (1968)

Anon. (1968)

The extent to which gas turbine smoke is a harmful pollutant is not presently well understood. Unlike that from diesel engines, gas turbine smoke is stated to contain negliglble carcinogenic components (Anon. (1965)). 
The major cause for public concern, to date, has been the aesthetic one of the smoke's distinct visibility. For example, in the exhaust stream of a Pratt and Whitney JT8D engine of the original design, solid carbon takes up roughly 20 billionths of the volume at take-off. This small amount does, however, absorb and scatter a considerable fraction of any light beam traversing it for a few feet or more, because the size of the particles is roughly the same as the wavelength of visible light. A mass output several orders of magnitude larger than that of the JT8D but with larger particles might look no worse (DeCorso et al. (1967)). While on a national basis the emission of particulates by gas turbine engines is small relative to that from other sources, in areas near airports they are the largest contributors (Anon. (1968)). Furthermore, the reduction of particulate emissions from other sources and the rapidy rising volume of jet aircraft traffic will both increase the relative magnitude of the problem (Fay (1970)). Lastly, in this day of the increasing degradation of the visual quality of our environment, the aesthetic argument against jet exhaust smoke has become a compelling one. Thus it is important that solid carbon be eliminated from the exhaust streams of jet aircraft as soon as possible.

The presence of solid carbon in jet aircraft exhaust may be blamed on either of two factors: the success of the formation mechanism, or the inadequacy of the subsequent oxidation. Thus both processes must be considered. Relevant data come from three different types of investigations: those examining the details of the chemical kinetics, those studying the carbon output of simple laboratory flames as functions of the operating conditions of the flame, and those recording the carbon output of gas 
turbine combustors (or engines) as a function of engine-operating parameters and design variables. At this time the state of knowledge of the kinetics of carbon formation is at a very basic level. A state-of-the-art review is given by Palmer and Cullis (1965). Not: only do no rate equations exist for kinetic calculations, it is not even clear which chemical species are important. The kinetics of carbon oxidation are understood considerably better, and useful rate equations exist, although here too there is some doubt as to the important species.

Lack of kinetic data has prohibited any quantitative prediction of the carbon output from a gas turbine combustor. A qualitative pico... ture of the important processes which lead to carbon formation can, however, be formed. This picture is based on data from flame studies and can explain the results of combustor exhaust measurements. A quantitative approach can be taken with carbon oxidation. As will be seen, the complexity of the combustor primary zone, where the fuel combustion takes place, allows only the crudest oxidation calculations there. However, a mathematical model of the combustor secondary zone, where the primary zone combustion products are diluted, may be used to provide the data necessary for integration of the oxidation kinetics equations. This understanding of the production and oxidation processes allows an assessment of the effects of design modifications on smoke emission levels. II. GAS TURBINE COMBUSTION

A. Combustor Description

The modern gas turbine combustor is the product of several decades of continuous refinement and evolution. Here, we will briefly consider 4 
the performance requirements that it must meet and their implications on its design. The primary function of the combustor is to raise the temperature of the compressor outlet air before entry to the turbine by mixing and burning with a hydrocarbon fuel. Compressor pressure ratios for modern aircraft engines are between 10 and 25 . This means, for example, that, at low altitude and full power, the air enters the combustor at a temperature of about $700^{\circ} \mathrm{K}$. Obviously an important requirement for engine efficiency is that the combustion process be virtually complete before the flow leaves the combustor; any unburnt fuel is a direct performance 1oss. Satisfactory combustion efficiency has not, however, been a major design problem.

It is desirable to operate the turbine at as high an inlet temperature as possible. In modern engines design of the turbine blades limits the turbine inlet temperature to about $1300 \mathrm{~K}$. This implies an overall equivalence ratio, $\phi_{0}$, for the combustor of about 0.25 . The equivalence ratio, $\phi$, is defined as the fuel-air ratio divided by the stoichiometric fuel-air ratio and "overal1" means across the entire combustor. A fuelair mixture with $\phi=0.25$ is well below the lean inflammability limit for hydrocarbon fuels in air (typically $\phi \approx 0.50$ ) and cannot be burned directly. The overall combustion process, then, is accomplished by dividing the combustor into a "primary zone," where enough air is mixed with the fuel to virtually complete the chemical reaction, and a "secondary or diluting zone" where the rest of the air is mixed in.

Within the constraint of the lean inflammability limit, the primary zone equivalence ratio, $\phi_{p}$, is determined by the requirements for marimum 
space utilization and rapid and reliable ignition. The former is especially important in aircraft engines, where weight is at a premium. Minimum combustor volume implies high intensity combustion (maximum chemical reaction rate) which fixes $\phi_{\mathrm{p}}$ near unity. The rapid ignition requirement, which is most stringent when applied to an airborne relight, is best met by primary zones which are slightly on the rich side of stoichiometric, in the range $1<\phi_{p}<1.3$ or so. A further requirement on aircraft engines is that the frontal area be minimized to reduce the engine's drag. This means that, for a given combustor volume, the shape will tend to be long and narrow. It furthermore implies that the mean flow velocity must be maximized, and thus that some sort of flame stabilization scheme will be necessary.

These considerations, combined with the need for stable engine operation over a wide range of power outputs (i.e., fuel flows) and operating pressures, result in the typical combustor configuration shown in Figure 1 , where the mean flow pattern is also indicated. The combustor consists of a liner, within which the highly turbulent combustion and mixing processes take place, and an annulus, where air flows until it is injected into the liner. Figure 1 may be regarded as a cross section of either an Individual can combustor (a typical aircraft engine will have 5-10 of these arranged azimuthally around the compressor drive shaft), or a section of an annular combustor. The flame stabilization mechanism is the recirculating flow pattern, which constantly brings hot combustion products to the fuel injector, serving as a continuous ignition source. The fuel is injected as a spray which breaks up into droplets which then vaporize; the vapor burns with the incoming fresh air. 
Air enters the combustor in three different ways. About 15 per cent of the air enters near the fuel spray and is given a rotational velocity which helps stabilize the flow pattern; this is the swirl air. About 25 per cent of the air is introduced parallel to the liner wall as film coolant to protect the liner from the extreme temperatures in the combusm tor. The remaining fraction, i.e., the bulk of the air, is injected as large jets designed for deep penetration and rapid mixing. It is the first row of large holes which drives the recirculating flow pattern, forming the primary zone. An interesting discussion of the combustor flow pattern is given by J. S. Clarke (1955, 1956).

There are, of course, other requirements which act as design constraints. Some of these result from the interaction between compressor, combustor, and turbine performance; some are empirical and are derived from past experience. It is not surprising, therefore, that although the considerations discussed above determine the overall combustor configuration, there are significant design variations between combustors developed by different engine manufacturers. B. The Combustion Process

The details of the combustion process in the gas turbine combustor are not well understood. The fuel enters the primary zone in the form of a spray, which rapidly breaks up into droplets with diameters off $50-200 \mathrm{~mm}$ and with speeds relative to the hot gases of the order of $70 \mathrm{~m} / \mathrm{sec}$. The combustor gases themselves are flowing in a complicated turbulent pattern with velocities of similar magnitude. The gases are at a temperature which is much higher than the boiling point of the fuel, so the droplets begin to vaporize as soon as they enter the combustor. 
This mass transfer process is greatly enhanced by the relative velocity between the droplets and the gases, which in turn is being reduced by the drag on the droplets.

Whether the droplets burn in the classical spherical flame manner, or whether they evaporate and the vapor mixes with air and burns elsewhere is determined by the relative time scales of the evaporation and deceleration processes. According to Spalding (1953), there is a critical relative velocity between a droplet and its surrounding gases, above which a flame cannot be maintained at the droplet's stagnation point. If the droplets slow down to this velocity before they have significantiy evaporated, they may be able to burn. However, even in this case the turbulent velocity fluctuations in the combustor may keep the relative velocity above the critical, thus preventing classical droplet combustion. Calculations reported by Heywood et al. (1970) indicate that by the time a typical droplet has decelerated to below the critical velocity, it has probably been mostly vaporized. Even if the droplet did not evaporate by the time it had lost its injection momentum, these calculations show that the turbulent velocity fluctuations would indeed prevent combustion.

Based on that analysis, the following picture of combustion in the primary zone can be drawn. There exists a very fuel-rich region near the injector face where the droplet evaporation is taking place, but where there is little combustion because of the lack of air. Either air (in the case of the swirl air), or air plus hot products (in the case of the mixture in the reverse flow region) flows by the fuel-rich zone entraining and mixing with the fuel vapor, and most of the combustion takes place as the flow travels downstream in the outer region of the zone. However, 
each bit of fuel must be mixed with about fifteen times its weight in air before it reaches stoichiometric proportions; therefore, considerable burning must take place at equivalence ratios substantially greater than unity. As will be seen later on, this rich burning is crucial for carbon formation.

The important physical processes occurring in the secondary zone are understood considerably better than those of the primary zone. Based on this understanding, a mathematical model can be developed for use in the calculation of soot particle burning rates. Heywood et al. (1970) and Martin (1968) have used the following assumptions: one-dimensional. flow, thermodynamic equilibrium except for the soot particles, no heat losses, and constant pressure. Heywood et al. (1970), whose model follows that developed by Graves and Grobman (1958), calculated the secondary zone mass flow rate as a function of distance fron the primary zone assuming a liner and annulus of constant circular cross-section and flush round air jet holes. Their data for mass flux, equivalence ratio, temperature and particle travel time, for a can geometry which approximates that of the IT8D combustor, for the case of $\phi_{\mathrm{p}}=1.2$ are shown in Figure 2. Martin (1968) did not calculate the mass flux, but instead imposed a linear vaxtam tion with distance which compares favorably with the data shown in Figure 2 . Assuming that the velocity and temperature of a fluid element are also those of a soot particle, the chemical kinetics equations describing soot partcle oxidation can be integrated to find the radius decrease of a soot particle travelling through a combustor secondary zone. This is discussed further in Section IV. 


\section{CARBON FORMATION}

\section{A. Data from Laboratory Flames}

Early experiments on the formation of solid carbon in laboratory flames were aimed at ranking various organic compounds according to "smoking tendency." No quantitative data as to the amount of soot formed were obtained. Typical of this research, and among the earliest, was that of Clarke et al. (1946), who worked with a free diffusion flame above circular pools of various organic liquids. The flame height could be varied by changing the diameter of the pool. They defined the "smoke point" as the length of the shortest flame which exhibited visible smoke, and since smoking tendency logically should be higher for lower smoke points, they let the smoking tendency be a constant times the inverse of the smoke point. Clark's results indicate that the most important factor determining the relative smoking tendency of hydrocarbon fuels is the carbon atom to hydrogen atom ratio of the molecule. Thus aromatic hydrom carbons were found to smoke more easily than alkynes, alkenes and paraffins, in that order. Smoking tendency also correlated with fuel volatility; i.e., the higher the boiling point of a fuel, the lower its smoke point. These results were extended considerably by Schalla et al. (1957). They worked with confined laminar diffusion flames, and thus could control the overall fuel-aix ratio. The relative smoking tendencies they determined were similar to those of Clarke et al. (1946). They also found that, for a given fuel, more smoke was produced by flames with higher fuelair ratios. They did not, however, determine quantitatively the amount of solid carbon produced. The effect of pressure on smoking tendency was studied; smoking tendency was found to increase with pressure. 
MacFarlane et al. (1964) determined quantitatively the carbon output of premixed laboratory flames. They give data at pressures up to $20 \mathrm{~atm}$, as a function of equivalence ratio. Their data for one fuel, n-pentane, and one of their two-flame configurations are shown in Figure 3. These data are typical of the fuels they tested and have a number of important features. First, their experiments indicate virtually no carbon formed at pressures below 10 atm or so. This is due to their particum Lar configuration and indicates the sensitivity of carbon formation data on flame geometry. Their burner was designed specifically for high pressure studies; they could not even get a stable flame at atmospheric pressure. Other investigators have obtained carbon from premixed flames at atmospheric pressure (Homann (1967)). Second, at a given pressure, no carbon is formed below a certain "critical" equivalence ratio, typically around 2.5 , and at higher equivalence ratios the amount formed does not vary greatly. The existence of a critical equivalence ratio was also observed by Homann (1967). Third, at a constant equivalence ratio, above the critical, the amount of carbon formed rises rapidly with increasing pressure.

Comparison of this carbon output data with calculated equilibrium compositions at the appropriate equivalence ratios and pressures indicates that the products of these flames are not in equilibrium. In fact, solid carbon does not appear in the equilibrium products of hydrocarbon-air combustion for $\phi<3$ or so. In a general sense, therefore, carbon can be regarded as a reaction intermediate whose consumption is very slow relative to the major gas phase reactions. Thus when a hydrocarbon flame is quenched immediately after completion of the important gas phase reactions, as in an unconfined diffusion flame or bunsen-type premixed flame, the carbon oxidation reaction is often never completed. 
This was indicated very clearly by Michael Faraday a century ago (Faraday (1910)). In his classic series of lectures, entitled "The Chemical History of a Candle," he demonstrated the presence of soot formation and soot oxidation zones in a candle flame. Under normal circunstances there may be no soot leaving a burning candle though its presence in the flame is indicated by the emission of black-body radiation. If the flame is prematurely quenched, the soot appears as a product. In the gas turbine combustion process, the rate of quenching is controlled by the air flow distribution. Thus the carbon oxidation reacm tion may or may not be frozen before completion depending on how rapidly cooling air is mixed in. This is explained further in Section IV.

\section{B. Carbon Formation in Combustors}

The data on carbon formation in laboratory flames in the previous section can now be combined with the picture of primary zone combustion developed in Section II for an examination of solid carbon formation in gas turbine combustors. The major consideration is the existence of regions of fuel-rich combustion; the data from laboratory flames indicate that solid carbon will be formed in these zones. It is also clear that most of the carbon must be formed in the area which is most fuel-rich, i.e., the region very close to the apex of the fuel spray cone. This is true regardless of whether the combustion is largely premixed or mostiy diffusion controlled. If it is premixed then there exist small buming pockets of various fuel/air ratios. In the richest areas more of these pockets will have equivalence ratios greater than the critical, thus forming more carbon. If the combustion is diffusion controlled, then the results of Schalla et a1. (1957), which indicate that more carbon is formed 
in richer flames, apply directly. These arguments also imply a rise In smoke output with mean primary zone equivalence ratio. Based on the laboratory flame data, another obvious prediction is that pressure level should be an important factor in determining gas turbine smoke emission levels.

Data on carbon produced in gas turbine combustors tend to confirm these expectations. Investigators have found that the variables most strongly affecting carbon output are operating pressure, mean primary zone equivalence ratio, the distribution of air flow into the primary zone, and the details of the mixing of this air with the fuel vapor. An example of the influence of pressure and primary zone equivalence ratio $\left(\phi_{p}\right)$ is seen in Figure 4, taken from Toone (1968), of Rolls-Royce. It should be remembered in this discussion that the relative air flow distribution for a given combustor is roughly independent of engine speed. Thus $\phi_{p} \propto \phi_{0}$, where $\phi_{0}$ is the overall combustor equivalence ratio. Figure 4 clearly shows the rise of smoke output with rises of either combustor pressure or $\phi_{\mathrm{p}}$ in a given combustor configuration. Note that one Photosmoke Unit (P.S.U.) is roughly the equivalent of an exhaust concentration of $1 \mathrm{Hg} / \mathrm{h}$.

A number of other studies have shown the dependence of smoke output on $\phi_{p}\left(\right.$ or $\left.\phi_{0}\right)$. Sawyer $(1969,1970)$ was able to correlate, very roughly, smoke outputs from different engines with their overall equivalence ratios. Bahr et al. (1969) of General Electric found large decreases in smoke outw put when combustors were modified so that a larger fraction of the aix enters the combustor earlier (thus lowering $\phi_{p}$ while keeping $\phi_{0}$ constant). That the combustor was modified makes this result ambiguous as the right modification can reduce smoke output without lowering $\phi_{p} \cdot$ Durrant (1968) of Rolls-Royce found a reduction in carbon concentration in the primary 
zone by a factor of 3 when $\phi_{p}$ was reduced by a factor of $5 / 6$. In Pratt and Whitney's smoke reduction program, Faitani (1968) was able to reduce the Von Brand Smoke Density of the exhausts of combustors of nearly the same configuration by factors of up to 10 by doubling the fraction of the total air flow entering the primary zone. Similar results were reported by Gleason and Faitani (1967). In contrast with these results, Butze (1952) found that smoke output at first increased as $\phi_{0}$ was lowered: then decreased. The reason for the increase is not clear. Various modifications to the combustor mixing processes have been studied for the purposes of smoke reduction. Bahr et al. (1969) and Faitani (1968) found that blowing air jets directly into the fuel cone sharply reduced carbon formation. Several investigations (Toone (1968), Durrant (1968), Faitani (1968), Lefebvre and Durrant (1960)) have shown that decreases in fuel spray cone angle can sharply increase the smoke output of a combustor. "Swirl cups," design modifications to increase the mixing effectiveness of the swirl air, were found to reduce smoke output (Bahr et al. (1969)), as were "airspray atmoizers," where air jets assist directly in the injection and atomization processes (Durrant (1968, 1969)). Increased pressure drop across primary zone air inlet holes has been shown to reduce smoke (Faitani (1968)).

The major effect of these design modifications is to minimize local deviations from the mean primary zone equivalence ratio by increased mixing. The logical extension of this concept is to completely mix the fuel and air before injecting them into the combustor. Then, as long as $\phi_{p}$ is less than the critical value of $\phi$ previously mentioned for premixed flames, there should be no smoke output at all. This has been tried, and exhaust 14 
smoke was virtually eliminated (Faitani (1968) and Durrant (1969)). However, such combustors have been found to have unacceptable stability limits, and it has been a major problem to prevent the fuel from cracking before it is burnt.

other investigators have examined the effect of pressure on smoke output and have reached conclusions similar to Toone's. Durrant (1969) and Faitani (1968) both correlate the exhaust smoke level of various engines with engine pressure ratio. There is, however, an ambiguity in the interpretation of the data when the pressure is increased in a given combustor. There is general agreement that this strongly increases smoke output (Toone (1968), Bahr et a1. (1969), Faitani (1968) Butze (1952)), and no doubt a large part of this increase is due to increased carbon formation in the actual burning process as indicated in the laboratory flame data. However, it has also been shown that increased combustor pressure reduces the fuel spray cone angle (DeCorso et a1. (1967) and Faitani (1968)). The relative importance of this effect in increasing carbon output is hard to estimate.

Other combustor variables which have been investigated are combustor gas velocity, combustor inlet temperature, fuel inlet temperature (Butze (1952)), fuel droplet size (Durrant (1968) and Faitani (1968)) and combusm tor exit temperature (Toone (1968), Faitani (1968) and Gross-Gronowski (1967)). The first four have been found to be relatively unimportant. The last, however, is important. It has been found that with virtually all other variam bles held constant, an increase in exit temperature decreases smoke output. The mechanism for this has nothing to do with the primary zone. It is increased carbon oxidation rates and will be discussed in the next section. Another area which has been explored for possible smoke reduction is that of fuel composition. Earlier in this section it was explained that 
in laboratory flame studies, smoking tendency decreased as fuel hydrogen content increased. This effect has been shown to carry over to gas turbine combustors--smoke output increases as fuel hydrogen content decreases (Bahr et a1. (1969), Lefebvre and Durrant (1960), Jonash et al. (1958)). The use of additives to prevent carbon formation has also been extensively investigated (Jonash et al. (1958), Shayeson (1967), Taylor (1967)). It has been found that additives can significantly reduce smoke output. Neither changing the fuel hydrogen content nor the use of additives is considered a practical method for eliminating exhaust smoke, however. Presently used jet fuels were chosen for their price and availability, neither of which will be sacrificed if there are alternative methods of smoke reduction. The use of additives is not promising because they tend to leave deposits on combustor and turbine surfaces. Furthermore, some of them result in poisonous (though invisible) exhaust emissions. The conclusions reached in these combustor and engine smoke reduction studies are the following: First, it is possible, without changing the fuel or significantly affecting combustor performance, to eliminate visible smoke from the exhaust of modern jet engines. Second, the way to do it is to either "lean out" the primary zone, blow air directly into the fuel cone, or both. General Electric and Pratt and Whitney have successfully eliminated smoke from their most recent large aircraft engines by using this approach.

There are, however, two problems with this smoke reduction technique which have as yet not been sufficiently explored. First, kinetic calculations by Heywood et a1. (1970) have indicated that nitric oxide emissions increase as the primary zone is made leaner. This prediction has been confirmed by recent data showing that the "smokeless" JT8D combustors emit 16 
40 per cent more nitric oxide (averaged over a landing or take-off cycle) than combustors of the original design (George et a1. (1969)). At the present time there is little pressure on the airlines to reduce nitric oxide emissions, as they are not visible, while smoke is. In the future, a restriction on nitric oxide emissions may make it more difficult to eliminate exhaust smoke.

Second, it is possible that large reductions in the visibility of exhaust smoke may be obtained without similar reductions in the mass emission level. Data on the new JT8D combustors show a 23 per cent decrease in exhaust carbon mass loading from the original design, again averaged over a landing or take-off cycle (George et al. (1969)), which must be contrasted with the nearly 100 per cent difference in exhaust visibility. As previously discussed, visibility of exhaust smoke is very sensitive to particle size; this probably explains the apparent discrepancy. If the amount of carbon exhausted into the atmosphere is to be controlled rather than just its visibility, this effect must be kept in mind.

IV. CARBON OXIDATION

The second process determining the amount of smoke in the exhaust of gas turbine engines is the burning of soot particles in hot combustion products. This chemical reaction has been shown to be significant in the combustion products of both fuel-lean and fuel-rich flames (Lee et a1. (1962), Tsibulevsky and Tesner (1966, 1967), Tesner and Tsibulevsky (1967a, 1967b), Fenimore and Jones (1967)). That carbon burn-up is important in determing gas turbine smoke emission levels has already been demonstrated. Toone (1968) observed very high carbon concentrations (up to $2600 \mu \mathrm{g} / \mathrm{l}$ ) in the fuel-rich region of the primary zone of an engine exhausting negligible 
smoke (carbon density in exhaust less than $10 \mu \mathrm{g} / \mathrm{l}$ ). Faitani (1968) and Gross-Gronowski (1967) have shown substantial decreases in smoke emission with increases of combustor exit temperature, apparently due to increased carbon burn-up. Faraday's experiment, previously discussed, indicated the importance of oxidation on the smoke "emission" level of a candle.

In general, the burning of solid particles, depending on the temperature and the particle size, may be controlled by either the diffuston of oxidant to the particle or by the chemical reaction rate at the surface. Particle sizes in gas turbine exhausts have been examined by several investigam tors. DeCorso et al. (1967) found typical particle diameters of $0.05-0.06 \mu \mathrm{m}$ with occasional particles up to $0.125 \mu \mathrm{m}$, and that these small particles could agglomerate to irregularly shaped clusters with dimensions of $0.6-0.8 \mathrm{\mu m}$. Faitani (1968) found particles of about $0.1 \mu \mathrm{m}$ diameter. Lieberman (1968) measured particle diameters in the exhaust of a regenerative turbine system burning No. 2 fuel oil and found particles of regular and irregular shape with diameters up to $1 \mu \mathrm{m}$. The composition of these exhaust particles has been measured by several of the above investigators and others, and it is generally agreed that they consist of about 96 per cent carbon by weight (Faitani (1968)); the rest hydrogen and oxygen. Essenhigh et al (1965) show that diffusion is always unimportant in the combustion of carbon particles with diameters of less than $25 \mu \mathrm{m}$, so only the surface reaction rate need be considered here.

Three major investigations of soot particle burning rates have come to the authors' attention: the work of Lee, Thring and Beer (1962), Fenimore and Jones (1967), and Tesner and Tsilbulevsky (1966, 1967, 1967a, 1967b). Each group has examined soot oxidation in product gases of various 
equivalence ratios, pressures, and temperatures. The region of oxygen, partial pressure, and temperature studied by each group is shown in Figure 5 along with the region of interest in gas turbine combustors (the region shown for Tesner and Tsibulevsky is that discussed in their $1967 \mathrm{~b}$ work and was estimated, as they did not report $\mathrm{p}_{\mathrm{O}_{2}}$ in their publications). It can be seen that all the investigations have been at oxygen partial pressures and temperatures which are lower than gas turbine conditions. Tesner and Tsibulevsky were not able to correlate their data over the range of their experiments. Fenimore and Jones correlated their data with the assumption that one tenth of all collisions of hydroxyl radicals with the particle surface remove a carbon atom. Lee et al. found the chemical reaction rate to be linear with oxygen partial pressure.

In spite of the fact that these oxidation data are not in the proper range, it was felt that extrapolation of Lee et al, and Fenimore and Jones burning-rate expressions to gas turbine combustor conditions would glve at least an estimate of soot consumption within the combustor. Figure 6 shows burning-rate expressions evaluated for particles in equilibrium products of $\mathrm{C}_{\mathrm{n}_{2}}$ /air combustion of different equivalence ratios. The combustor air inlet temperature was calculated assuming ambient air conditions of 1 atm. and $300^{\circ} \mathrm{K}$ and a compressor efficiency of 87 per cent. For a spherical particle, the surface recession rate is the rate of change of radius. Though there are significant differences between the two correlations, in the most important region, $0.7<\phi<1.1$, the predictions are of comparable magnitude. Lee-Thring-Beer's correlation would not be expected to hold for fuel-rich mixtures since all their data were taken in the presence of significant $0_{2}$ concentrations. 
These burning rates indicate what was previously observed experimentally, that significant amounts of the soot produced in the fuel-rich regions of the primary zone can be consumed in the other regions of the primary zone and in the secondary zone. For example, a spherical particle spending $3 \mathrm{msec}$ in near-stoichiometric $(0.8<\phi<1.2)$ products in the primary zone would undergo a radius change of about $0.1-0.3 \mu \mathrm{m}$, depending on the pressure (using the Fenimore-Jones data), or up to twice these figures in the leanex regions, using the Lee-Thring-Beer data. Heywood et al. (1970) and Martin (1968) have done more extensive calculations of carbon burn-up in the secondary zone, using the fluid mechanic models previously discussed. Radius changes in the secondary zone of similar magnitude to these primary zone values were reported. Note that conditions giving maximum soot burn-up rates (i.e., roughly stoichiometric combustion prodw... ucts) also result in maximum nitric oxide formation rates (Heywood et al (1970)).

A comparison of these calculated radius changes with particle sizes observed in the combustor exhaust indicates that carbon oxidation plays an important role in determining the smoke emission level of an engine. If the data from these extrapolated correlations are correct, then, to reach the exhaust without being consumed, a soot particle may have to spend most of its time travelling in the relatively cooler areas of the combustor near the liner.

V. CONCLUSIONS

The most important conclusion reached in this study is the following: The exhaust smoke concentrations of modern jet aircraft engines can be 
lowered below visible levels using the techniques reviewed here. This has primarily involved adding air to the fuel rich zones of the combustor by increasing the total amount of air entering the primary zone or by modifying the air flow paths. These changes have been made without sacrificing other desirable engine characteristics. With increasing engine pressure ratios and new design constraints involving other pollutants, it will, however, be increasingly difficult to solve the smoke problem by merely varying the combustor design until one that works is found.

It is therefore clear that a better understanding of the controlling processes in the primary zone must be obtained. The details of the process by which the fuel vapor and air $\mathrm{mix}$ and burn are not known. This must be explored before the production of carbon, or any other pollutant, can be adequately modelled. At this point it is not even known whether mixing, chemical kinetics, or neither controls the rate of fuel consumption in the primary zone. The reaction kinetics involved in the formation of solid carbon need further work. To date fundanental kinetic studies of carbon formation have contributed little to the understanding of the formation process in practical systems. Similarly the data on carbon oxidation kinetics need clarification and must be extended to the regions of interest in gas turbine systems. The calculations reviewed here indicate that oxidam tion may play an important role in determining carbon emission levels, but the uncertainty in the kinetic data carries over to this conclusion. 


\section{REFERENCES}

Anon., 1965, "Studies of Atmospheric Pollution in the Department of Science," Prefecture de Police Paris Laboratoire Municipal, cited by Durrant, T. 1968, "The Control of Atmospheric Pollution from Gas Turbine Engines," SAE Paper 680347.

Anon., 1968, "Nature and Control of Aircraft Engine Exhaust Emissions," Report No. 1134-1, Northern Research and Engineering Corp., Cambridge, Mass.

Bahr, D. W., Smith, J. R., and Kenworthy, M. J., 1969, "Development of Low Smoke Emission Characteristics for Large Aircraft Turbine Engines," AIAA Paper 69-493.

Butze, H. F., 1952, "Effect of Inlet-Air and Fuel Parameters on Smoking Characteristics of a Single Turbular Turbojet Engine Combustor, "NACA RM E52AI8.

Clarke, A. E., Hunter, T. G., and Garner, F. A., 1946, "The Tendency to Smoke of Organic Substances on Burning, Pt. I," J. Inst. Petr., 32 , $627-642$.

Clarke, J. S., 1955, "The Relation of Specific Heat Release to Pressure Drop in Aero-gas-turbine Combustion Chambers, "Joint Conference on Combustion, Inst. Mech. E. and A.S.M.E., 354-361.

Clarke, J. S., 1956, "A Review of Some Combustion Problems Associated with the Aero Gas Turbine," J. Royal Aero. Soc., 60, 221-237.

DeCorso, S. M., Hussey, C. E., and Ambrose, M. J., 1967, "Smokeless Comm bustion in Oil Burning Gas Turbines," ASME Paper 67-PWR-5.

Durrant, T., 1968, "The Control of Atmospheric Pollution from Gas Turbine Engines," SAE Paper 680347.

Durrant, T., 1969, "The Reduction of Smoke from Gas Turbine Engines," presented to 9 th International Aeronautical Congress, A.F.I.T.A.E. . Paris.

Essenhigh, R. H., Froberg, R., and Howard, J. B., 1965, "Combustion Behavior of Small Carbon Particles," Ind. and Eng. Chem., 57, 32-43.

Faitani, J. J., 1968, "Smoke Reduction in Jet Engines through Bumer Design," SAE Paper 680348.

Faraday, M., 1910, "The Chemical History of a Candle," Harvard Classics,

Vol. 30 (P. F. Collier and Son, New York). 
Fay, J.A., 1970, "Air Pollution from Future Giant Jetports," M.I.I. Fluld Mechanics Lab. Report No. 70-6.

Fenimore, C. P.and Jones, G. W., 1967, "Oxidation of Soot by Hydroxy 1 Radicals," Journal of Physical Chemistry, 71, 593-597.

Fiore11o, S. C., 1968, "The Navy's Smoke Abatement Program," SAE Paper 680345.

George, R. E., and Burlin, R. M., 1960, "Air Pollution from Comerctal Jet Aircraft in Los Angeles County," Los Angeles Air Pollution Control. District, Los Angeles, Calif.

George, R. E., Verssen, J. A., and Chass, R. I., 1969, "Jet Aircraft: A Growing Source of Pollution," J. Air Pollution Control Assoc. 19, $847-855$.

Gleason, J. G. and Faitani, J. J., 1967, "Smoke Abatement in Gas Turbine Engines through Combustor Design," SAE Paper 670200.

Graves, C. C. and Grobman, J. S., 1958, "Mathematical Analysis of TotalPressure Loss and Airflow Distribution for Tubular Turbojet Combustors with Constant Annulus and Liner Cross-Sectional Areas," NACA Report 1373.

Gross-Gronowski, L., 1967, "Smoke in Gas-Turbine Exhaust," ASME Paper 67-WA/GT-5.

Heywood, J. B., Fay, J, A., and Linden, L. H., 1970, "Jet Aircraft Air Pollutant Production and Dispersion," AIAA Paper 70-115.

Homann, K. H., 1967, "Carbon Formation in Premixed Flames," Combustion and Flame, 11, 265-287.

Jonash, E. R., Wear, J. D., and Cook, W. P., 1958, "Effect of Fuel Varlam bles on Carbon Formation in Turbojet Engine Combustors, "NACA Report 1352.

Lee, K., Thring, M., and Beer, J., 1962, "On the Rate of Combustion of Soot in a Laminar Soot Flame," Combustion and Flame, 6, 137-145.

Lefebvre, A. I. and Durrant, T., 1960, "Design Characteristics Affecting Gas Turbine Combustion Performance," presented to National Aeronautical Meeting, SAE, Los Angeles.

Lieberman, A., 1968, "Composition of Exhaust from a Regenerative Turbine System," J. Air Pollution Control Assoc., 18, 149-153.

Lozano, E. R., Melvin, W. W., and Hochheiser, S., 1968, "Air Pollution Emissions from Jet Engines," J. Air Pollution Control Assoc., Vol. 18, 392-394. 
MacFarlane, J. J., Holderness, F. H., and Whitcher, F. S. E., 1964, "Soot Formation Rates in Premixed $\mathrm{C}_{5}$ and $\mathrm{C}_{6}$ Hydrocarbon Air Flames at Pressures up to 20 Atmospheres," Combustion and Flame, 8 , 215-229.

Martin, F. J., 1968, "Soot Oxidation in a Model Combustor," General Electric Research and Development Center, Schenectady, New York, Report No. 68-C-352.

Palmer, H. B. and Cullis, C. R., 1965, "The Formation of Carbon from Gases," Chemistry and Physics of Carbon, ed. P. L. Walker (Marcel Dekker, New York), I.

Sawyer, R. F., 1969, "Fundamental Processes Controlling the Air Pollution Emissions from Turbojet Engines," AIAA Paper 69-1040.

Sawyer, R. F., 1970, "Reducing Jet Pollution Before It Becomes Serious," Astronautics and Aeronautics, $8,62-67$.

Schalla, R. L. and Hibbard, R. R., 1957, "Smoke and Coke Formation in the Combustion of Hydrocarbon-Air Mixtures," Chapter IX, NACA Report 1300.

Shayeson, N. M., 1967, "Reduction of Jet Engine Exhaust Smoke with Fuel Additives," SAE Papex 670866.

Spalding, D. B., 1953, "Experiments on the Burning and Extinction of Liquid Fuel Spheres," Fue1, 32, 169-185.

Taylox, W. G., 1967, "Smoke Elimination in Gas Turbines Burning Distillate 0i1," ASME Paper 67-PWR-3.

Tesner, P. A. and Tsibulevsky, A. M., 1967a, "Gasification of Dispersed Carbon in Hydrocarbon Diffusion Flames, III. Flames of AcetyleneHydrogen and Acetylene Water Vapor Mixtures," Comb. Expl. and Shock Waves, 3(2), 163-167 (1969)(translation from Fizika Goreniya i Vzryva, $3(2), 261-267$.

Tesner, P. A. and Tsibulevsky, A. M., 1967b, "Kinetics of Dispersed Carbon Gasification in Diffusion Flames of Hydrocarbons, "Combustion and Flame, 11, 227-233.

Toone, B., 1968, "A Review of Aero Engine Smoke Emission," Cranfield International Symposium Series, Vo1. 10, Combustion in Advanced Gas Turbine Systems, ed. I. E. Smith (Pergamon Press).

Tsibulevsky, A. M. and Tesner, P. A., 1966, "Gasification of Dispersed Carbon in Hydrocarbon Diffusion Flames, I. Acetylene-Nitrogen Flames," Comb. Expl. and Shock Waves, 2(2), 38-42 (1969) (translation from Tizika Goreniya i Vzryva, $2(2), 61-67$.

Tsibulevsky, A. M. and Tesner, P.A., 1967, "Gasification of Dispersed Carbon in Hydrocarbon Diffusion Flames, II. Smoky Flames, "Comb. Expl. and Shock Waves, 3(1), 64-68 (1969) (translation from Fizika Gorenfya i Vzryva, $3(1), 1 \overline{0} 5-110$. 


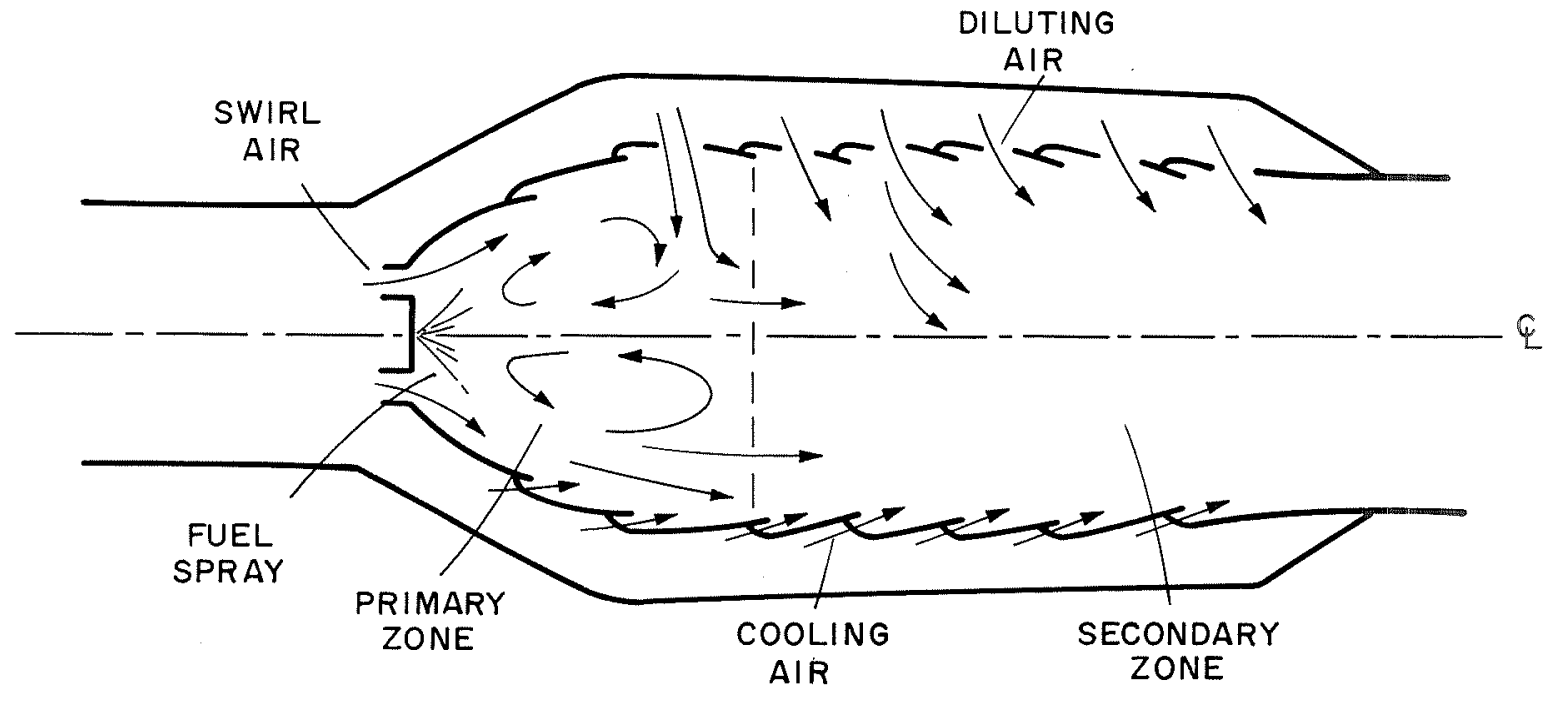

Fig. I - Cross-section of a Typical Combustor 


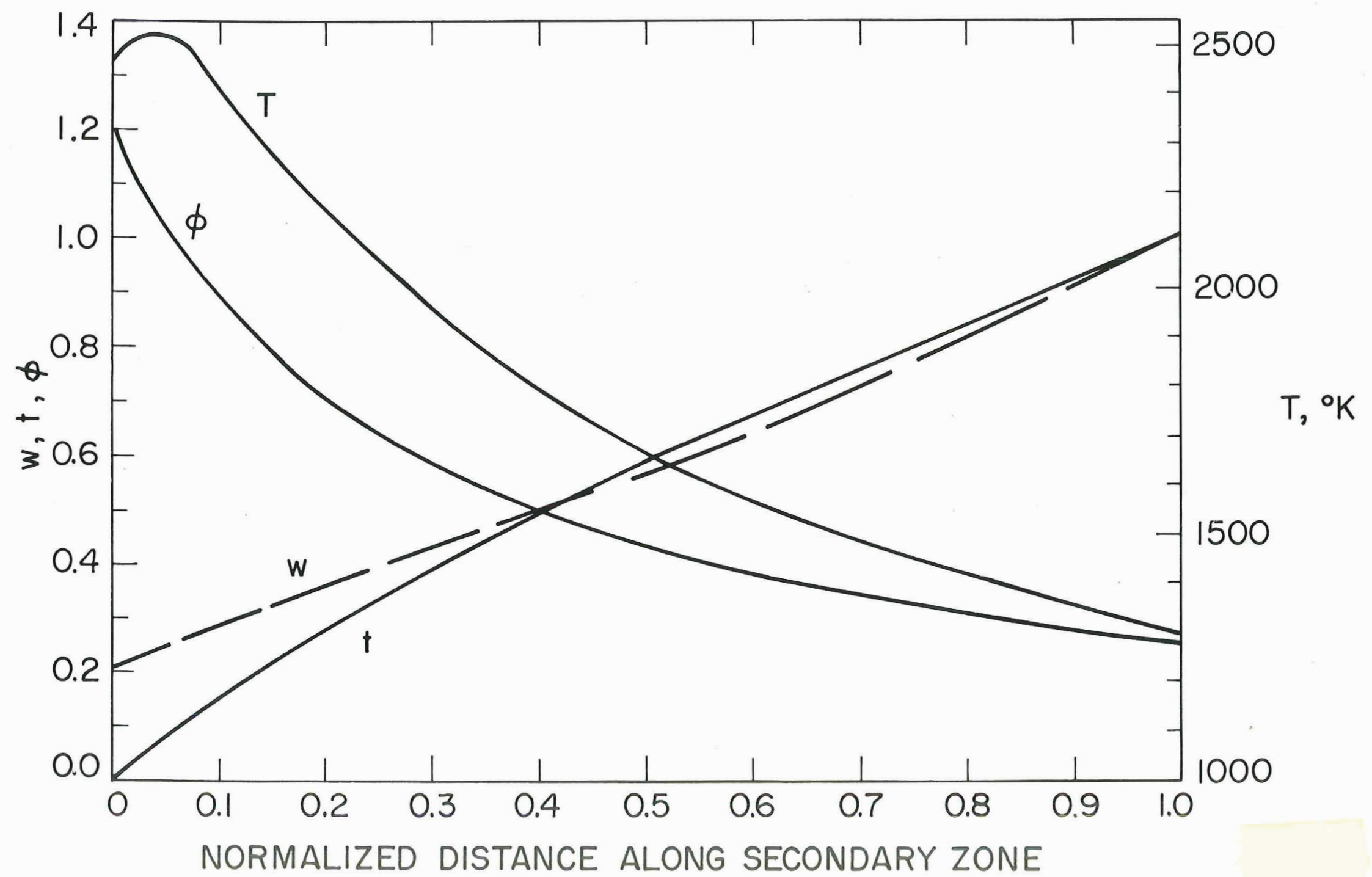

Fig. 2 - Results of a one-dimensional model secondary zone calculation for $\mathrm{C}_{\mathrm{n}} \mathrm{H}_{2 \mathrm{n}}$ fuel burned with $700 \mathrm{OK}$, 15 atm air. Mean primary zone equivalence ratio is 1.2. Mean gas temperature T, equivalence ratio $\phi$, normalized travel time $t$ (time after entry into secondary zone/secondary zone residence time) and normalized liner mass flux (local mass flux/mass flux at secondary zone exit) are shown as a function of normalized position along the secondary zone. Secondary zone length was 1 foot. 


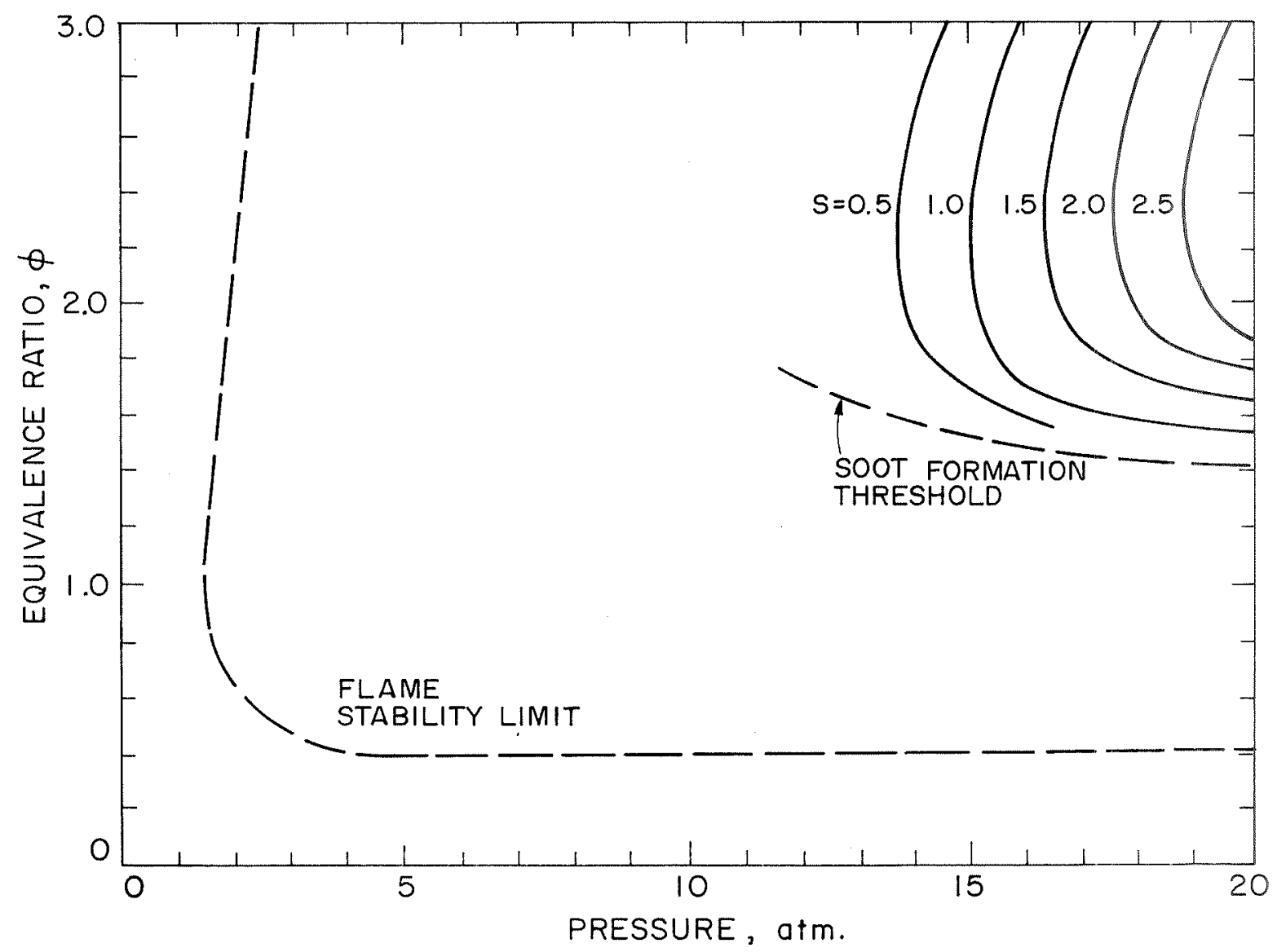

Fig. 3 - Effect of pressure and equivalence ratio on soot formation ratio for premixed n-pentane-oxygen combustion. Soot formation ratio $\mathrm{S}$ is percentage of fuel carbon atoms which emerge from the flame as soot. From MacFarlane et al. (1964). 


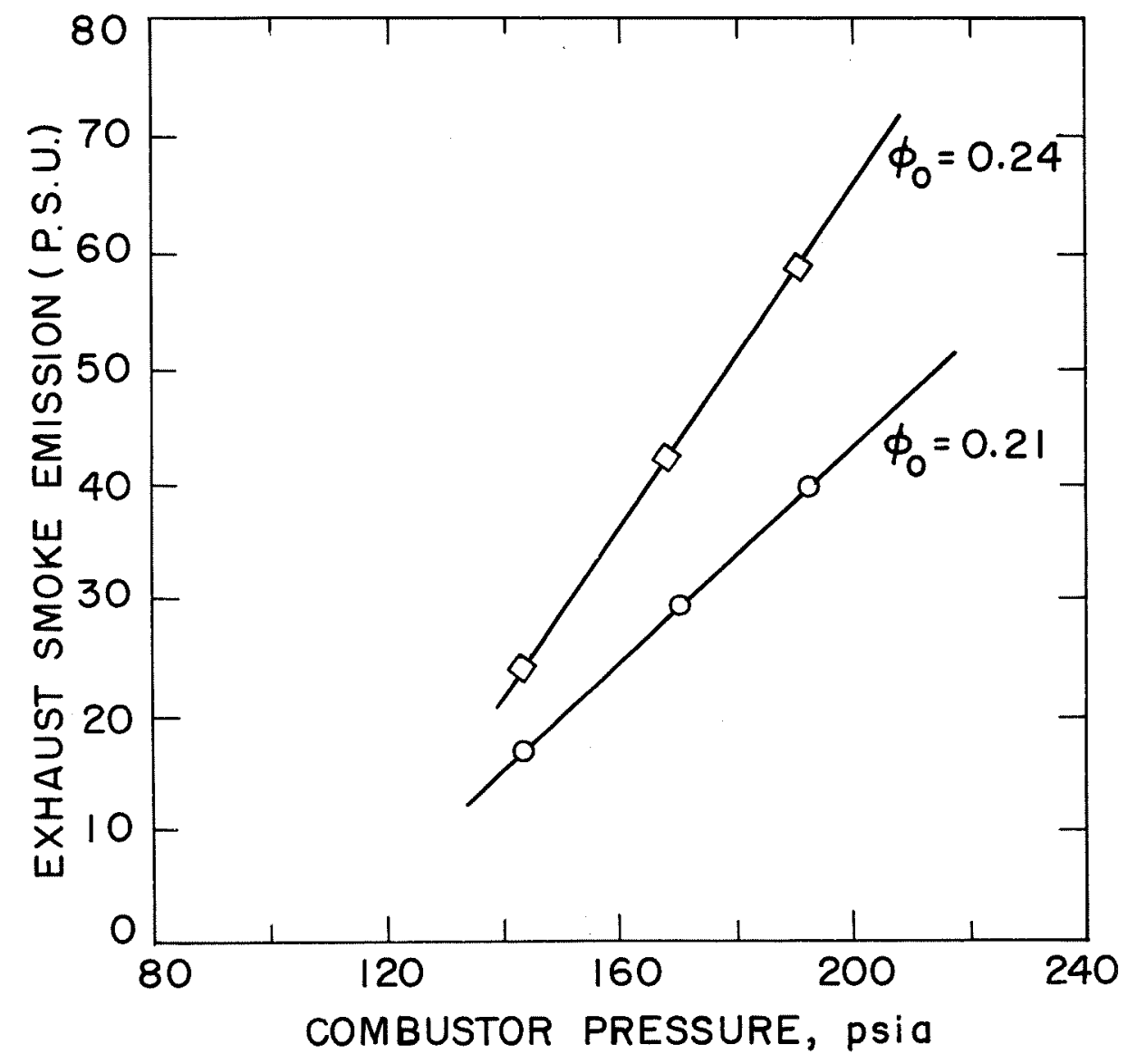

Fig. 4 - Effect of combustor pressure and overall equivalence ratio on smoke emission of Rolls-Royce RA.24 engine. P.S.U. (photo smoke unit) $\simeq 1$ g carbon per litre. From Toone (1968). 


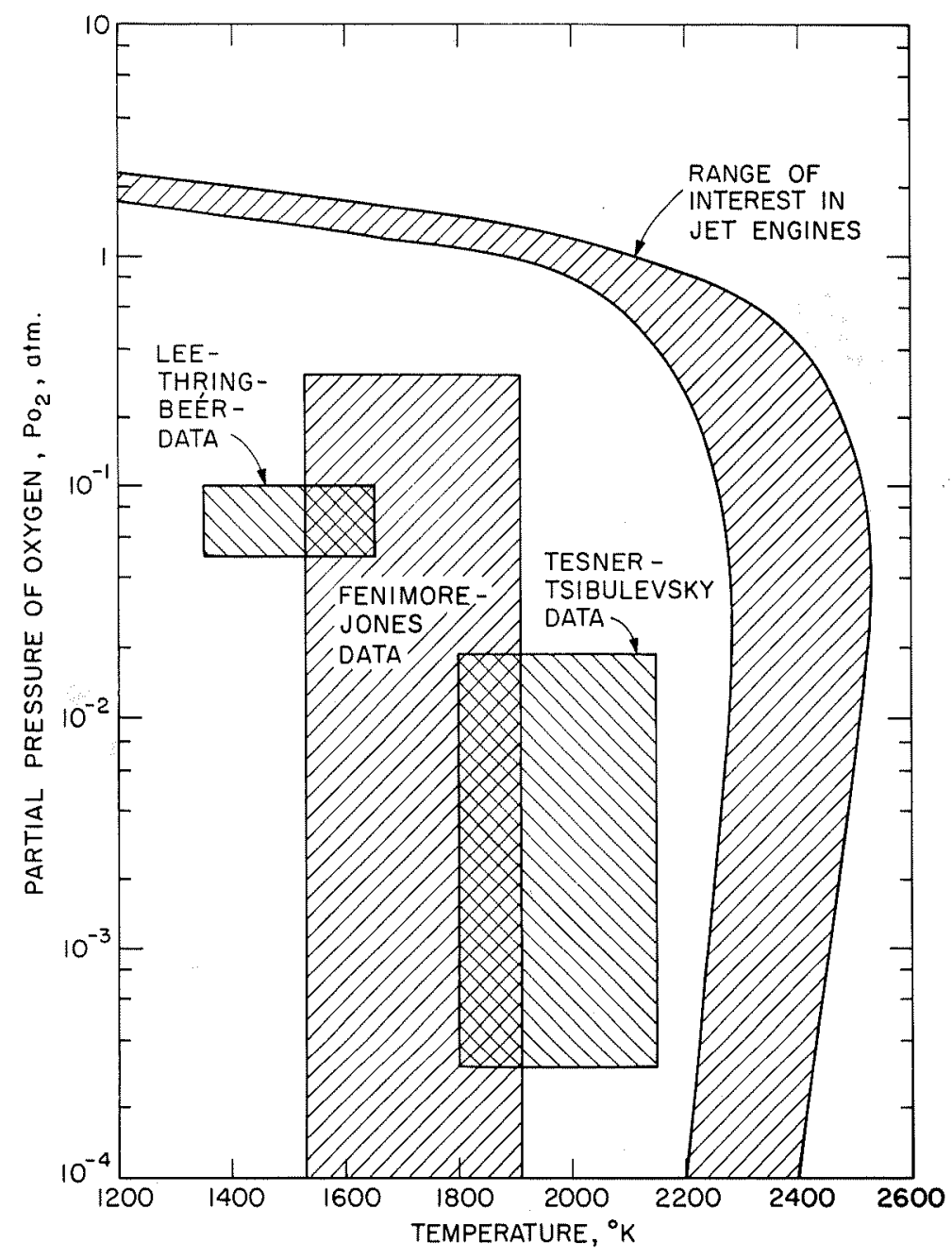

Fig. 5 - Regions of available carbon oxidation data compared with region of interest in fet engines. 


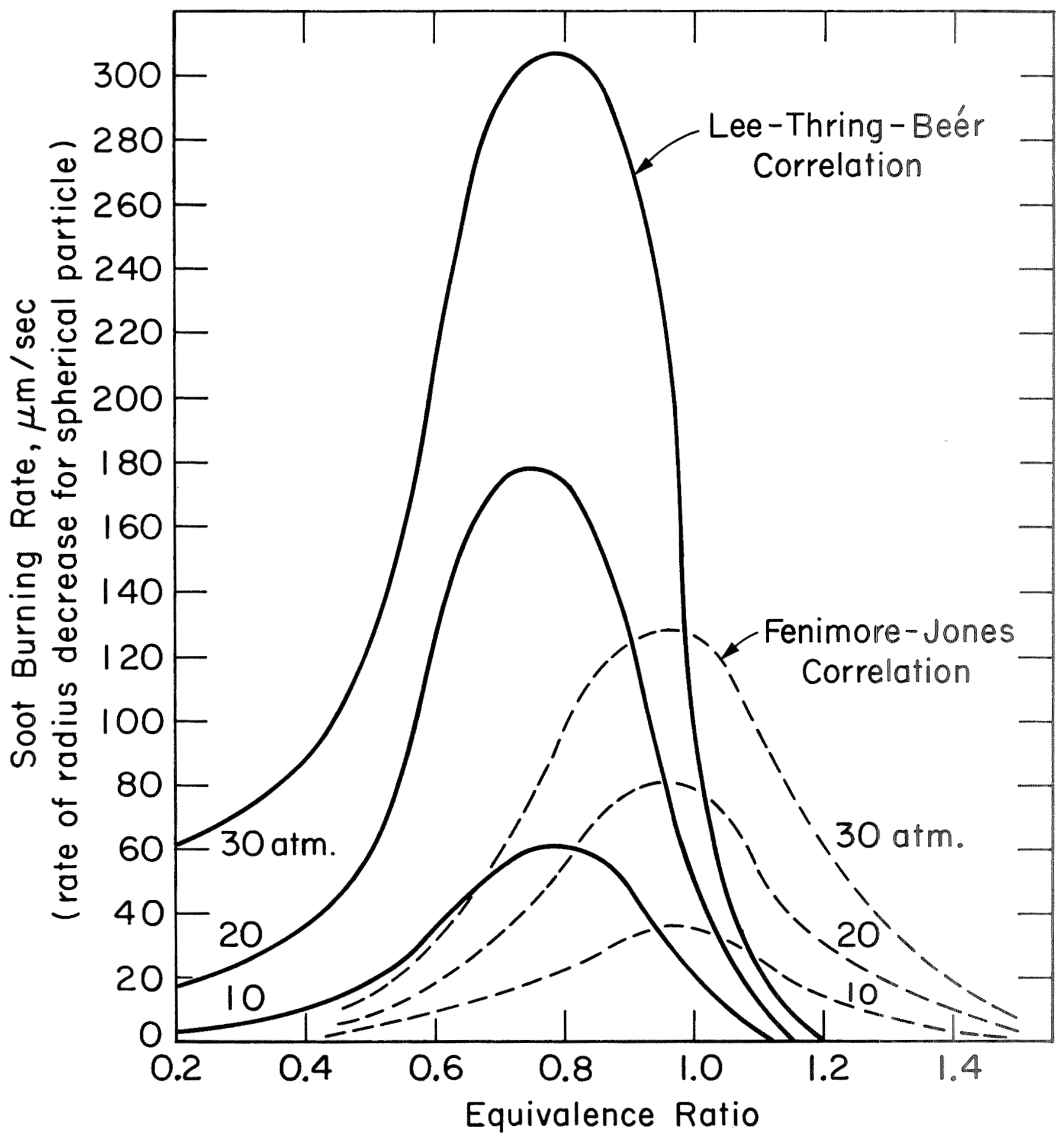

Fig. 6 - Calculated burning rates of soot particles in adiabatic combustion products of kerosene $\left(\mathrm{C}_{\mathrm{n}} \mathrm{H}_{2 \mathrm{n}}\right)$ and air at 10, 20, and $30 \mathrm{~atm}$. Combustor inlet air temperatures are 621, 765 , and $865^{\circ} \mathrm{K}$. Soot burning rate expressed as a surface recession rate. 


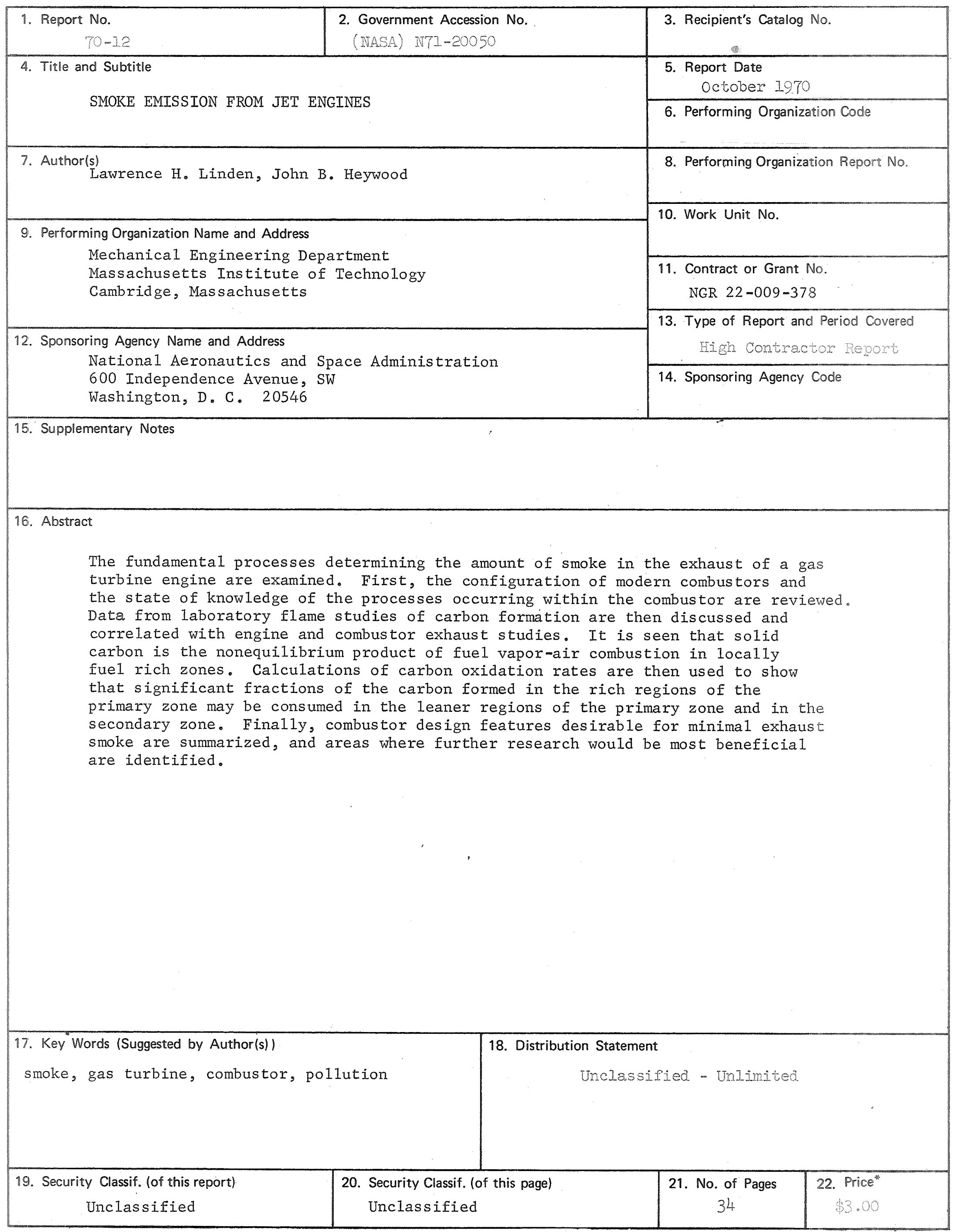

*For sale by the National Technical Information Service, Springfield, Virginia 22151 